\title{
A Dynamic Approach in Production Management for Automotive Field
}

\author{
Banu Özkeser* \\ Koluman Otomotiv Endüstri A.Ş. R\&D Center, Mersin, Turkey
}

\begin{abstract}
Solution proposals, based on dynamic approaches, can easily take place of the existing situations owing to the unlimited customer requests. Therefore, this may lead to a rapid transformation, triggering the manufacturing society to deal with the requirements for a sustainable competitive advantage. Especially, the automotive field, deeply affected by the fast-changing demands, brings about some new business models superimposing the existing ones because of the technology-intensive production management. This progress makes the world's expectation be higher depending on process innovation and minimizing the lead time may be declared as one of the top satisfaction points in the market. This paper, including the review of different manufacturing methods, highlights the awareness of the best implementations along with the production management in the automotive field. Moreover, the final objective is to develop a process innovation by designing a dynamic algorithm. The content of the paper, depending on multiple machines with multiple orders, is completed in all details by analyzing the gaps of the literature review. In the second step, the original algorithm is formed by taking into consideration the priorities. The achieved analysis is based on the main criteria and subcomponents of the scheduling of the manufacturing process. Finally, the algorithm, formed by four main priorities, leads the numerical implementations to be done in only one order and the results show that this approach can be a good way for minimization of total delays of orders. The results approve that the algorithm minimizes the delay and helps the customer increase their satisfaction.
\end{abstract}

Keywords: Automotive, Production Management, Manufacturing Methods, Process Innovation

\section{INTRODUCTION}

The production activities have become complicated due to the developing production techniques and growing production systems, and become out of control with simple production activities. Manufacturing processes which could be coped with simple approaches in the past, has become more detailed due to tool and technological improvements. However, it is inevitable that companies, using innovative approaches, will be successful in competition as they can use production management more effectively.

While planning in production management; long, medium and short term plans are taken into account. For the long term, it is foreseen that takes place from two to ten years; In the medium term, plans between one year and two years are taken into consideration. In product management, which includes short-term planning; the fact that orders have unique processing rows and preparation times depending on the processing sequence also makes process innovation in order to improve processes inevitable. Job-shop production sys- tems, especially used in the automotive industry, is a production system that is not easy to realize production management due to its structure. The large number of orders in the job-shop type production system, each order's having its unique processing order and preparation time depending on the process order make the solution more complex.

Since the system is mostly dynamic, algorithms close to the optimum solution are preferred. The performance criterion required for each system may not be the same. The goal in this paper is to minimize the delivery time of the orders and balance the machines' usage capacities with the designed algorithm.

This paper is about an order-type production system with $k$ workstations, where $\mathrm{d}_{\mathrm{i}}$ delivery time and work route is random, with certain $n$ jobs, coming to the system at random.

A wide literature survey is completed that addresses the approaches developed within the scope of production management and especially in the automotive field. 
Panwalker and Iskander classified the order of the jobs and priorities depending on four main factors. They are; earliest due date, implementation of the simple rules in the different queues in the same system, weighted prioritization and heuristic algorithms. All these are tested and the results are vary from each other in terms of real conditions. The results of their study show the system needs revision adapting to all possibilities [1].

In Sun and Lin's study, it is assumed that each job has its processing route, each machine can do only one job at the same time and it's impossible to stop the machines until the process is completed while a process is undertaken, Moreover, how long time each process has is presumably known. In this algorithm, the set of jobs waiting in front of a machine can be known precisely, the order to start the first operation can be determined and it is possible to calculate the delivery of a new job. In this respect, the algorithm has superiority over other approaches. However, they stated that in the calculation of delivery times, further studies should be done in order to get better results in minimizing the flow times and finishing the works on time [2].

Another study is completed on a technique that offers robust solutions to production scheduling problems. According to this study, makespan value is considered as a performance criterion. The makespan value is defined from the start time of the process to the last finish time [3].

Duenyas and Van Oyen aims to reduce the average waiting cost in a system with single-service parallel heterogeneous queues. First of all, in a two-tailed system, they developed an intuitive algorithm to determine the most accurate time for one job to move to another queue, and they tested this rule with simulation technique in many tailed systems and stated that the heuristic method they developed is effective in many problems [4].

In another paper, in which an interactive decision support system is developed for the solution of scheduling problems, the implemented steps are follows:

1. Identification of parameters that are important in decision making and measurement of these parameters

2. Determination of scheduling parameters

3. Specification of a control parameter as a time qualifier

4. Developing a better system to get rid of the bottlenecks of the current system

5. Defining an objective parameter for grouping the operations on each machine

6. Defining the procedure to be developed [5]

Godin stated that, in systems where re-scheduling was performed, the computer should not be used as a decision maker, but in pre-application information such as making calculations and testing decisions, rather than as decision maker, as there were shortcomings in the model [6].

Vancheeswaran and Townsend take into account the subject to minimize the delays arising from the failure to comply with the delivery times of the orders, and the delay time is tried to be minimized with integer programming technique. In large systems, the difficulty of applying the technique has been demonstrated as it requires a lot of computation time [7].

Blackstone, Phillips and Hogg examined analytical approaches and simulation techniques on which of the pending jobs will be put into the first process. They found that even in small workshop models, analytical studies have become very complex. They said that in distribution systems producing workshops, no distribution rules give optimal results. They emphasized that charts using more than one rule rather than a single rule give better results [8].

Buxey investigated the theoretical approaches developed for scheduling problems in production systems and their applications in practice. Production scheduling is divided into four main groups: scheduling resources, delivering to orders, scheduling backwards according to deliveries and assigning priority orders and assignment to machines. He stated that while mathematical models can be successful in the first three groups, analytical approaches are not fully modeled with analytical approaches in determining the priority order of jobs and assigning them to machines, and the models are not flexible enough. He added that mathematical models and analytical approaches can be successful in small businesses in three other groups and in production systems where unexpected events are very rare [9].

Metaxiotis, Askounis, and Psarras divided the solutions of scheduling problems into two main groups as algorithmic approaches and remodeling approaches. After creating the mathematical model of the scheduling problem, they defined solutions such as integer or dynamic programming as algorithmic approaches that maximize the goal function or find solutions that are close to the best with intuitive approaches, and said that the model should be enriched in order to meet the desired targets in the remodeling approach. They said that after scheduling problem was modeled in algorithmic approaches, it focused on solution models, solutions were sought by creating different constraints and resources in the model for a satisfactory solution in re-modeling, and methods that gave quick results could be selected in the solution method. Considering that people spend 80-90\% of their time in scheduling problems in determining the constraints of the problem and $10-20 \%$ of their time in scheduling, enrichment of the decision-support systems with the modeling approach can be the main contribution of the modeling without human intervention, and this type of approach is better in scheduling problems. They stated that they produced solutions [10].

Kerr and Ebsary have tried to develop a decision support model that can schedule the production system by making use of the experience of the decision maker who created the scheduling in the production system and the methods de- 
veloped by the decision maker. They systematized the methods they use as an intuitive rule. Besides, they made calculations with the computer and loaded the machine for both current scheduling and possible situations. Thus, they have established a system where very fast and alternative scheduling is done [11].

In another study, it is indicated that the will to reduce vehicular traffic in cities, to improve its regulation have made smart mobility an increasingly important topic during the last years. As a consequence, automotive companies have begun to develop electric vehicles and related components. In this context, a well known Italian company operating in automotive field, is giving its important contribution working on many research projects concerning vehicle electrification. The presentation of paper is mainly the report of the activities concerning the design of the production process, along with the development of the FMEA [12].

Given the recent dynamics of the automotive industry, the ability for a firm to be flexible has often taken priority over other performance indicators. Using the notion of distinct business models and trade-offs as our theoretical lens, the purpose of this study was to pay attention to lean manufacturing, a different approach. Data was obtained from 140 automotive companies and implementing agile production methods were found to be more flexible in comparison with firms implementing lean production methods [13].

\section{MATERIALS AND METHOD}

In order to keep production under control, the enterprise must have a dynamic infrastructure. Instant information of both orders and machines is needed for applying dynamic scheduling algorithms. In the developed algorithm, information such as average workloads on machines, average queue waiting times and remaining idle times of orders will be needed.

The main features of the production system discussed in this study are listed below:

- More than one product is produced. The product range is very wide, since the study was carried out in an order-based enterprise.

- The work order followed by each product is different. It is also possible to arrive new orders with unknown transaction order, although the transaction route is generally known.

- Multiple machines perform similar operations.

- Product order sizes are different. Even if orders of very large size have come, production is made in one lot and the order is not divided.

- The unit capacities of the machines are determined.

- Delivery times of orders are clear. Delivery times are determined when the order is placed.

- Some machines have preparation times depending on the previous process.

Assumptions:

- Preparation times were considered as part of the waiting time in the queue and did not need to be considered separately.

- It is assumed that the machines operate without malfunction in line with their unit capacities.

- Machines that do the same job have the same capacity.

- Transport times between workstations have been neglected.

- Workstations cannot refuse incoming orders.

- Reprocessing of orders has been ignored.

- Overtime is out of the question.

- Due to the orders route, they can visit the same workstation more than once.

The notation used in the formulation of the problem is as follows:

i: order number i:1....n

$\mathrm{k}$ : work station number k:1...s

$\mathrm{D}_{i}$ : delivery time of $\mathrm{i}$. order

Z: today's date

$\mathrm{q}_{\mathrm{i}}$ : the quantity of $\mathrm{i}$ order

S: the idle time of the i order (without waiting)

$\mathrm{S}_{\mathrm{ibek}}$ : the idle time of the $\mathrm{i}$ order (with waiting)

$\mathrm{ORT}\left(\mathrm{W}_{\mathrm{k}}\right)$ : average queue waiting time of $\mathrm{k}$ workstation

ORT $\left(W_{i(k \rightarrow n}\right)$ : avarage waiting time for the next station after $\mathrm{k}$ workstation of i order

$\mathrm{P}_{\mathrm{k}}$ : the queue length of $\mathrm{k}$ workstation (numbers)

$\operatorname{ORT}\left(\mathrm{P}_{\mathrm{k}}\right)$ : avarage the queue length of $\mathrm{k}$ workstation (numbers)

$\operatorname{ORT}\left(\mathrm{P}_{\mathrm{i}(k \rightarrow n}\right)$ : avarage the queue length for the next station after $\mathrm{k}$ workstation of $i$ order

$t_{i k}$ : the process time of $\mathrm{i}$ order in $\mathrm{k}$ workstation

$t_{i(k \rightarrow \rightarrow))}$ : the unit process time after $k$ workstation of $i$ order

$\mathrm{X}_{\mathrm{i}}$ : time to reach the station $\mathrm{k}$ of the delayed order $\mathrm{i}$ (minute)

$\mathrm{G}_{\mathrm{k}}$ : A set of parts that will delay the $\mathrm{k}$ station

Kk: Set of parts delays waiting at the $\mathrm{k}$ station

Bk: A set of parts with possible delays at the $k$ station

hk: Time to reach the minimum $\mathrm{k}$ station of the delayed parts that will stop by the $\mathrm{k}$ station (minute)

Mk: Set of time to finish the work of the machines at the $\mathrm{k}$ station

Ykm: $\mathrm{m}$ machine at the $\mathrm{k}$ station to be assigned

$\mathrm{I}_{\mathrm{i}}$ : the last Workstation of $\mathrm{i}$ order

In the algorithm development phase, the main goal was determined as minimization of delay times, four different priority situations were revealed by examining the situations that might be encountered in this direction and these situ- 
ations were tried to be formulated to minimize the delays.

The designed algorithm has four priorities, explained in below:

1. priority: Parts previously reported to stop by the station

$\mathrm{S}_{\mathrm{i}}$ is calculated for the parts waiting in the queue of all stations in the system. If a negative $S_{i}$ value is found, a signal is sent to all workstations that the order will undergo. In this signal, the times for the parts to reach the relevant workstations are the times when the processing times are taken into account, for which the delays are not taken into account. In the light of this information, when assigning a machine, the first priority is, of course, late orders and delivery times.

When a part comes out of the machine at the workstation and it is decided which part to replace; this workstation will first investigate whether there are any delayed parts of its workstation with reported reach time. If there are no parts reported, it takes the $2^{\text {nd }}$ priority. If any delayed parts are reported, it is checked if there is a machine that will go into empty state before the delayed part reaches the station. if any, it takes the second priority, otherwise the empty machine waits for the delayed part to be reported. Here is the notation of this first priority:

Define $\mathrm{G}_{\mathrm{k}}$ set

If $\mathrm{G}_{\mathrm{k}}=\varnothing$, go to 2. priority

If $G_{k} \neq \varnothing$ and $h k>\min \left(M_{k}\right) \notin Y_{k m}$, go to 2. priority

If $G_{k} \neq \varnothing$ and $h k<\min \left(M_{k}\right) \notin Y_{k m}$, assign the part having $h_{k}$ value to the empty machine and arrange $X_{\text {ik }}$ for the selected part

2. priority: waiting parts that occurred while waiting in the queue

The beginning of the signal logic occurs at this step. Delayed parts are detected by the system for the first time at this stage and signals are sent to almost all workstations. When a part is removed from the machine at the workstation and which part is to be replaced, the idle times of the parts waiting to be processed are calculated first. If a negative value is found, it signals. Then, the idle time weighted in the queue with the waiting times is determined. What is meant here is that whichever of the workstations it will drop by for the order, the average waiting time is greater, and that the workstation should have more idle time. Selects the order with the smallest value to be processed. Here is the notation of this second priority:

Calculate $\mathrm{S}_{\mathrm{i}}=\mathrm{D}_{\mathrm{i}}-\mathrm{Z}-\left(\right.$ ti $\left.\times \mathrm{q}_{\mathrm{i}}\right)$

If $\mathrm{Si} \nless 0$, go to 3. priority

If $\mathrm{Si}<0$, assign the min $\left(\mathrm{S}_{\mathrm{i}} \times\left[\mathrm{ORT}\left(\mathrm{W}_{\mathrm{k}}\right) / \mathrm{ORT}\left(\mathrm{W}_{\mathrm{i}(\mathrm{k} \rightarrow \mathrm{n})}\right)\right.\right.$ value to the empty machine

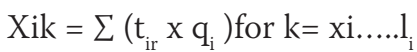

3. priority: Parts that may be delayed
In cases where there are no orders to be delayed, new idle times are calculated by taking into account the average queue waiting times in the workstations, they will stop for the parts waiting in the queue. The aim here is to find out which of them are candidates to be late if the orders continue their normal route. If the ratios are evaluated as a result of the calculations, these parts are important and priority parts for the system. Among them, the order with the smallest weighted idle time is selected to be traded on the empty machine. If no negative value is found, $4^{\text {th }}$ priority is passed. Here is the notation of the third priority:

Calculate $\mathrm{S}_{\text {ibek }}=\mathrm{Di}-\mathrm{Z}-\sum\left(\left(\mathrm{t}_{\mathrm{ir}} \mathrm{x}_{\mathrm{i}}\right)+\mathrm{ORT}\left(\mathrm{W}_{\mathrm{k}}\right)\right)$

If $\mathrm{S}_{\text {ibek }} \nless 0$, go to 4 . Priority

If $\mathrm{S}_{\text {ibek }}<0$, assign the min $\left(\mathrm{S}_{\mathrm{ibek}} \mathrm{x}\left[\mathrm{ORT}\left(\mathrm{W}_{\mathrm{k}}\right) / \mathrm{ORT}\left(\mathrm{W}_{\mathrm{i}(\mathrm{k} \rightarrow \mathrm{n})}\right)\right.\right.$ value to the empty machine

\section{4. priority: workload balancing}

When there are no delayed or delayed parts, priorities to balance the workloads of the machines take the first place. This process is tried to be done by sending parts from the stations where the orders will go, to those with low workload and by not sending parts to stations with high workload except emergency parts. For this purpose, workstations first calculate their workload. Here is the number of parts in the queue meant as workload. If the number of parts in the queue is more than the average number of parts in the queue, this means the workstation is dense. The notation is explained below:

If $\mathrm{P}_{\mathrm{k}}>\operatorname{ORT}\left(\mathrm{P}_{\mathrm{k}}\right)$, assign the part having tha value of min $\left(\mathrm{t}_{\mathrm{ik}}\right.$ $\left./ t_{i k n}\right)$ to the empty machine

If $\mathrm{P}_{\mathrm{k}}<\mathrm{ORT}\left(\mathrm{P}_{\mathrm{k}}\right)$, assign the jobs of $\mathrm{P}_{\mathrm{i}(\mathrm{k} \rightarrow \mathrm{n})}<\mathrm{ORT}\left(\mathrm{P}_{\mathrm{i}(\mathrm{k} \rightarrow \mathrm{n})}\right)$ to the the empty machine having $\max \left(\mathrm{t}_{\mathrm{i}(\mathrm{k} \rightarrow \mathrm{n})}\right)$

If $\mathrm{P}_{\mathrm{k}}<\mathrm{ORT}\left(\mathrm{P}_{\mathrm{k}}\right)$, assign the other jobs except for $\mathrm{P}_{\mathrm{i}(\mathrm{k} \rightarrow \mathrm{n})}<\operatorname{ORT}\left(\mathrm{P}_{\mathrm{i}(\mathrm{k} \rightarrow \mathrm{n})}\right)$ to the the empty machine having $\min \left(t_{i(k \rightarrow n)}\right)$

\section{RESULTS AND DISCUSSION}

The algortihm is implemented in the manufacturing line of a company, in automotive field. There are three machines in $k$ workstation and one of them is empty.

\section{1. sample}

Initially, $\mathrm{X}_{\mathrm{ik}}$ workstation and $\mathrm{M}_{\mathrm{i}}$ are calculated.

\begin{tabular}{|c|c|}
\hline$M_{i}$ & times of $M_{i}$ \\
\hline $\mathrm{M}_{2}$ & 50 \\
\hline$M_{3}$ & 120 \\
\hline \multicolumn{2}{|c|}{ Table 2. $\mathrm{M}_{\mathrm{i}}$ time of the $1^{\text {st }}$ sampl } \\
\hline$X_{i k}$ & $\mathrm{X}_{\mathrm{ik}}$ access time \\
\hline$X_{5 k}$ & 15 \\
\hline$x_{7 k}$ & 90 \\
\hline
\end{tabular}

The minimum reach time of delayed parts is 15 minutes.

The minimum time of the running machines is 50 minutes. 
Since $15<50$, the $\mathrm{M}_{\mathrm{i}}$ machine waits for the $\mathrm{X}_{5 \mathrm{k}}$ order.

\section{2. sample}

Initially, $\mathrm{X}_{\mathrm{ik}}$ workstation and $\mathrm{M}_{\mathrm{i}}$ are calculated.

Table 3. Access time of the $2^{\text {nd }}$ sample
\begin{tabular}{|c|c|}
\hline$M_{i}$ & times of $M_{i}$ \\
\hline$M_{2}$ & 15 \\
\hline$M_{3}$ & 120 \\
\hline \multicolumn{2}{|c|}{ Table 4. $M_{i}$ time of the $2^{\text {nd }}$ sample } \\
\hline$X_{i k}$ & $X_{i k}$ access time \\
\hline$X_{5 k}$ & 50 \\
\hline$X_{7 k}$ & 90 \\
\hline
\end{tabular}

The minimum reach time of delayed parts is 50 minutes.

The minimum time of the running machines is 15 minutes.

Since $50>15$, the $M_{i}$ machine goes to second priority because $M_{2}$ machine will be empty before passing through the $X_{5 k}$ workstation.

Table 5. $\mathrm{S}_{\mathrm{i}}$ value for the parts waiting in the queue
\begin{tabular}{|c|c|}
\hline ORT $\left(\mathrm{W}_{\mathrm{k}}\right)$ & ORT $\left(\mathrm{W}_{\mathrm{i}(\mathrm{k} \rightarrow \mathrm{n}}\right)$ \\
\hline- & - \\
\hline 5 & 10 \\
\hline 10 & 100 \\
\hline
\end{tabular}

\begin{tabular}{|c|c|}
\multicolumn{3}{|c|}{ Table 6. ORT $\left(\mathrm{W}_{\mathrm{i}(\mathrm{k} \rightarrow \mathrm{n}}\right)$ value } \\
\hline $\mathrm{S}_{\mathrm{i}}$ & $\mathrm{X}_{\mathrm{ik}}$ access time \\
\hline $\mathrm{S}_{4}$ & 50 \\
\hline $\mathrm{S}_{6}$ & -5 \\
\hline $\mathrm{S}_{7}$ & -20 \\
\hline
\end{tabular}

\section{3. sample}

Initially, $\mathrm{X}_{\mathrm{ik}}$ workstation and $\mathrm{M}_{\mathrm{i}}$ are calculated.

Table 7. Access time of the $2^{\text {nd }}$ sample
\begin{tabular}{|c|c|}
\hline$M_{i}$ & times of $M_{i}$ \\
\hline$M_{2}$ & 15 \\
\hline$M_{3}$ & 120 \\
\hline \multicolumn{2}{|c|}{ Table 8. $M_{i}$ time of the $2^{\text {nd }}$ sample } \\
\hline$X_{i k}$ & $X_{i k}$ access time \\
\hline$X_{5 k}$ & 50 \\
\hline$X_{7 k}$ & 90 \\
\hline
\end{tabular}

The minimum reach time of delayed parts is 50 minutes.

The minimum time of the running machines is 15 minutes.

Since $50>15$, the $M_{\mathrm{i}}$ machine goes to second priority because $M_{2}$ machine will be empty before passing through the $X_{5 k}$ workstation.

Table 9. $S_{i}$ value for the parts waiting in the queue
\begin{tabular}{|c|c|}
\hline$S_{i}$ & time \\
\hline$S_{4}$ & 50 \\
\hline$S_{6}$ & 10 \\
\hline$S_{7}$ & 5 \\
\hline ORT $\left(W_{k}\right)$ & ORT $\left(W_{i(k \rightarrow n}\right)$ \\
\hline- & - \\
\hline- & - \\
\hline- & - \\
\hline
\end{tabular}

Table 9. (Cont.)

\begin{tabular}{|c|c|}
\hline $\mathrm{S}_{\mathrm{i}}$ & time \\
\hline $\mathrm{S}_{4}$ & 50 \\
\hline $\mathrm{S}_{6}$ & 3 \\
\hline $\mathrm{S}_{7}$ & -7 \\
\hline $\operatorname{ORT}\left(W_{k}\right)$ & $\operatorname{ORT}\left(\mathrm{W}_{\mathrm{i}(\mathrm{k} \rightarrow \mathrm{n}}\right)$ \\
\hline - & - \\
\hline - & - \\
\hline 10 & 100 \\
\hline
\end{tabular}

\section{4. sample}

Initially, $\mathrm{X}_{\mathrm{ik}}$ workstation and $\mathrm{M}_{\mathrm{i}}$ are calculated.

\begin{tabular}{|c|c|}
\hline$X_{i k}$ & $\mathrm{X}_{\mathrm{ik}}$ access time \\
\hline$X_{5 k}$ & 50 \\
\hline$X_{7 k}$ & 90 \\
\hline \multicolumn{2}{|c|}{ Table 11. $M_{i}$ time of the $2^{\text {nd }}$ samp } \\
\hline$M_{i}$ & times of $M_{i}$ \\
\hline $\mathrm{M}_{2}$ & 15 \\
\hline$M_{3}$ & 120 \\
\hline
\end{tabular}

The minimum reach time of delayed parts is 50 minutes.

The minimum time of the running machines is 15 minutes.

Since $50>15$, the $\mathrm{M}_{\mathrm{i}}$ machine goes to second priority because $M_{2}$ machine will be empty before passing through the $X_{5 k}$ workstation.

\section{CONCLUSION}

While the main target of businesses was profitability etc., today, the main target has become customer satisfaction. Establishing a system that will provide products or services that satisfy customers is the basic criterion of success. In this context, scheduling algorithms help companies to set up and manage systems with the process innovation it creates. In this way, we can provide services to the customer without delay on the specified delivery date, and we can also make progress on issues such as efficient use of resources and profitability. Although there are many sources on the subject in the literature, static systems are generally emphasized and dynamic studies are not included. Heuristic algorithms are taken into consideration as well as algorithms for the optimal result. The problem addressed in this study is the multiple order problem that is encountered especially in the automotive industry. The purpose of the developed algorithm, a process innovation, is to minimize the delay times of the orders and balance the machine capacities. A certain target has been determined in the algorithm and many possibilities are tried to be formulated. The study was based on the production of orders in only one lot. If algorithms are developed on the basis that lots can be divided, more improved results can be obtained. It is assumed that the machine times that perform the same operation are the same and this acceptance can be changed in future studies. Machine stoppages, rework, etc. are ignored. These issues can also be addressed in the future. 


\section{REFERENCES}

[1] Panwalkar, S. S., Iskander, W. (1977). A Survey of Scheduling Rules. Operations Research, 25(1): 45-61. doi:10.1287/opre.25.1.45

[2] Sun, D., Lin, L. (1994). A dynamic job shop scheduling framework: a backward approach. The International Journal of Production Research, 32(4): 967-985.

[3] Tjornfelt-Jensen, M., Hansen, T. K. (1999). Robust solutions to job shop problems. In Proceedings of the 1999 Congress on Evolutionary Computation-CEC99 IEEE (Cat. No. 99TH8406) 2: 1138-1144.

[4] Duenyas, I., Van Oyen, M. P. (1996). Heuristic scheduling of parallel heterogeneous queues with set-ups. Management Science, 42(6): 814-829.

[5] Banerjee, S., Banerjee, A., Burton, J., Bistline, W. (2001). Controlled partial shipments in two-echelon supply chain networks: a simulation study. International Journal of Production Economics, 71(1-3): 91-100.

[6] Godin, V. B. (1978). Interactive scheduling: historical survey and state of the art. AllE Transactions, 10(3): 331-337.

[7] Vancheeswaran, R., Townsend, M. A. (1993). Two-stage heuristic procedure for scheduling job shops. Journal of Manufacturing Systems, 12(4): 315-325.

[8] Blackstone, J. H., Phillips, D. T., Hogg, G. L. (1982). A state-of-the-art survey of dispatching rules for manufacturing job shop operations. The International Journal of Production Research, 20(1): 27-45.

[9] Buxey, G. (1989). Production scheduling: Practice and theory. European Journal of Operational Research, 39(1): 17-31.

[10] Metaxiotis, K. S., Askounis, D., Psarras, J., (2002), Expert systems in production planning and scheduling: A state-of-the-art survey. Journal of Intelligent Manufacturing, 13(4), 253-260.

[11] Kerr, R., Ebsary, R. (1988). Implementation of an expert system for production scheduling. European journal of operational research, 33(1), 17-29.

[12] Righettini, P., Strada, R., Gosatti, A., Togni, S., Camozzi, F., Fissore, C. (2019). Smart Mobility: a modern approach to automotive product development for vehicle electrification. 2019 IEEE 5th International Forum on Research and Technology for Society and Industry (RTSI). doi:10.1109/rtsi.2019.8895541

[13] Qamar, A., Hall, M. A., Collinson, S. (2018). Lean versus agile production: flexibility trade-offs within the automotive supply chain. International Journal of Production Research, 56(11): 3974-3993. 